\title{
Mass identification of potential service sector donors of personal protective equipment from an online directory during the COVID-19 pandemic
}

\author{
Calvin Diep ${ }^{1}$ (D) Akash Goel ${ }^{2} \cdot$ Karim S. Ladha $^{2,3}$ \\ Received: 23 April 2020 / Accepted: 3 May 2020 / Published online: 27 May 2020 \\ (C) The Canadian Public Health Association 2020
}

\section{Dear Editor:}

In fighting the COVID-19 pandemic, healthcare facilities and healthcare professionals (HCPs) are experiencing severe shortages of personal protective equipment (PPE) such as gloves, gowns, and respirators (Ranney et al. 2020). Recognizing that PPE is essential to protect frontline workers from infection and cross-contamination, healthcare institutions, public health organizations, and governments are trying urgently to improve the available supply.

The Journal of the American Medical Association recently issued a call for ideas to address these shortages (Bauchner et al. 2020). One common theme was to "retrieve" PPE from existing supplies in the community, such as from local dentists, veterinarians, and nail salons (Livingston et al. 2020). Hospitals here in Toronto opened donation sites but, early on, lacked a centralized effort to actively procure PPE from the service sector.

To address this, our grassroots taskforce ("PPE for HCPs Toronto") developed a proof of concept algorithm in Python (v2.7) to identify potential service sector donors in the public directory: http://www.YellowPages.ca. Using this algorithm, we compiled a list of all 4489 dentists, veterinarians, estheticians, tattooists, contractors, and painters in the Toronto metropolitan area. On March 24, our volunteers began cold calling and e-mailing them to seek donations.

Calvin Diep

calvin.diep@mail.utoronto.ca

1 Faculty of Medicine, University of Toronto, 1 King's College Cir, Toronto, ON M5S 1A8, Canada

2 Department of Anesthesiology and Pain Medicine, University of Toronto, 123 Edward St, Toronto, ON M5G 1E2, Canada

3 Department of Anesthesia, St. Michael's Hospital, 30 Bond St, Toronto, ON M5B 1W8, Canada
In our first week, we contacted 2640 businesses and received a response from 473 (17.9\%). Ultimately, 110 (4.2\%) agreed to donate or stated they had already done so. These efforts yielded 80,000 pairs of gloves, 2000 gowns, 6000 surgical masks, and 700 N95 respirators. Our algorithm has been used to provide lists of target businesses to similar taskforces in twelve other regions in Canada, which have seen comparable success so far.

The low response rates we experienced can be attributed to the recommendations made by the provincial government for non-essential businesses to close starting March 23-one day before we began soliciting donations (Rocca and Westoll 2020). Had we developed the algorithm and begun contacting businesses earlier, we might have retrieved a PPE stockpile many times larger in our first week.

This experience highlights the importance of having plans in place to mobilize resources proactively during public health crises. While cold calling is resource-intensive, our results show it is a worthwhile effort. In the future, public health units and governmental organizations may benefit from algorithms similar to ours that can quickly identify potential sources of PPE in the community (Gilmore and Singh 2020). Working with designated taskforces to contact these sources early could mitigate anticipated PPE shortages. This could also support government buyback schemes from the local service sector, especially when international trade may become restricted (Reynolds 2020). Ultimately, these measures could be implemented as part of orchestrated efforts to equip frontline HCPs with sufficient PPE during a pandemic response.

Acknowledgements We would like to acknowledge the leadership team at PPE for HCPS Toronto, comprised of Yezarni Wynn, Thulasie Manokaran, Alexa Goodbaum, Mia Kibel, Tul-Zahra Rida, and Sophia Duong, for their tireless efforts coordinating this operation. To learn more about this grassroots initiative, please visit https://www.PPEforHCPsTO.ca/. 
Funding information Dr. Karim S. Ladha is supported in part by a Merit Award from the Department of Anesthesiology and Pain Medicine at the University of Toronto (Toronto, Canada).

\section{Compliance with ethical standards}

Disclaimer The opinions, results, and conclusions reported in this article are those of the authors and are independent from the funding sources.

Conflict of interest The authors declare that they have no conflict of interest.

\section{References}

Bauchner, H., Fontanarosa, P. B., \& Livingston, E. H. (2020). Conserving supply of personal protective equipment - a call for ideas. Journal of the American Medical Association. https://doi. org/10.1001/jama.2020.4770.

Gilmore, R., \& Singh, M. (2020). Feds continue to seek masks, other PPE after admitting stockpile 'likely' not enough. CTV News. https:// www.ctvnews.ca/health/coronavirus/feds-continue-to-seek-masksother-ppe-after-admitting-stockpile-likely-not-enough-1.4880269. Accessed 30 March 2020.

Livingston, E., Desai, A., \& Berkwits, M. (2020). Sourcing personal protective equipment during the COVID-19 pandemic. Journal of the American Medical Association. https://doi.org/10.1001/jama. 2020.5317.

Ranney, M. L., Griffeth, V., \& Jha, A. K. (2020). Critical supply shortages - the need for ventilators and personal protective equipment during the COVID-19 pandemic. The New England Journal of Medicine. https://doi.org/10.1056/NEJMp2006141.

Reynolds, C. (2020). Coronavirus: Canada looks to secure PPE, but 68 countries have restricted exports. Global News. https://globalnews. ca/news/6769162/canada-medical-supplies-coronavirus/. Accessed 15 April 2020.

Rocca, R., \& Westoll, N. (2020). Coronavirus: all non-essential workplaces ordered to close in Ontario. Global News. https://globalnews. ca/news/6717022/ontario-doug-ford-coronavirus-covid-19-march23/. Accessed 30 March 2020.

Publisher's note Springer Nature remains neutral with regard to jurisdictional claims in published maps and institutional affiliations. 